\title{
Reporting performance of prognostic models in cancer: a review
}

Susan Mallett ${ }^{1 *}$, Patrick Royston ${ }^{2}$, Rachel Waters ${ }^{1}$, Susan Dutton ${ }^{1}$, Douglas G Altman ${ }^{1}$

\begin{abstract}
Background: Appropriate choice and use of prognostic models in clinical practice require the use of good methods for both model development, and for developing prognostic indices and risk groups from the models. In order to assess reliability and generalizability for use, models need to have been validated and measures of model performance reported. We reviewed published articles to assess the methods and reporting used to develop and evaluate performance of prognostic indices and risk groups from prognostic models.

Methods: We developed a systematic search string and identified articles from PubMed. Forty-seven articles were included that satisfied the following inclusion criteria: published in 2005; aiming to predict patient outcome; presenting new prognostic models in cancer with outcome time to an event and including a combination of at least two separate variables; and analysing data using multivariable analysis suitable for time to event data.

Results: In 47 studies, Cox models were used in 94\% (44), but the coefficients or hazard ratios for the variables in the final model were reported in only $72 \%$ (34). The reproducibility of the derived model was assessed in only $11 \%$ (5) of the articles. A prognostic index was developed from the model in $81 \%$ (38) of the articles, but researchers derived the prognostic index from the final prognostic model in only $34 \%$ (13) of the studies; different coefficients or variables from those in the final model were used in 50\% (19) of models and the methods used were unclear in $16 \%$ (6) of the articles. Methods used to derive prognostic groups were also poor, with researchers not reporting the methods used in 39\% (14 of 36) of the studies and data derived methods likely to bias estimates of differences between risk groups being used in $28 \%$ (10) of the studies. Validation of their models was reported in only $34 \%$ (16) of the studies. In 15 studies validation used data from the same population and in five studies from a different population. Including reports of validation with external data from publications up to four years following model development, external validation was attempted for only $21 \%$ (10) of models. Insufficient information was provided on the performance of models in terms of discrimination and calibration.
\end{abstract}

Conclusions: Many published prognostic models have been developed using poor methods and many with poor reporting, both of which compromise the reliability and clinical relevance of models, prognostic indices and risk groups derived from them.

\section{Background}

Prognosis is central to medicine, often being used to direct diagnostic pathways and to inform patient treatment $[1,2]$. Most clinicians use patient and disease characteristics to predict patient outcome. For accurate outcome prediction, multiple risk factors need to be considered jointly because single factors have insufficient predictive value to distinguish patients who are likely to do well from those likely to do poorly.

\footnotetext{
*Correspondence: susan.mallett@csm.ox.ac.uk

${ }^{1}$ Centre for Statistics in Medicine, Wolfson College Annexe, University of Oxford, Linton Road, Oxford, OX2 6UD, UK
}

Prognostic models allow multiple risk factors to be used systematically, reproducibly and using evidence based methods [2-5]. Prognostic models are also referred to as clinical prediction models, clinical prediction rules, risk scores and nomograms. Although a large number of prognostic models are published, very few models are used in clinical practice [3].

To understand whether a particular prognostic model or prognostic index provides a useful tool to inform patient treatment, the accuracy of the model predictions need to be reported, both in terms of how well the model separates individuals who develop the outcome from
C Biomed Central

(C) 2010 Mallett et al; licensee BioMed Central Ltd. This is an Open Access article distributed under the terms of the Creative Commons Attribution License (http://creativecommons.org/licenses/by/2.0), which permits unrestricted use, distribution, and reproduction in any medium, provided the original work is properly cited. 
those that do not (discrimination) and how close the predicted risks are to the actual observed risks (calibration). Currently several measures of model performance are used, although there is no consensus on which are the most clinically useful given the range of different clinical decisions directed from prognostic models [6].

This article examines how prognostic models are used to develop clinical predictions about cancer patients, and the measures of model performance that are used.

We assessed, by a systematic review, the methods used in 47 articles on prognostic models where the specific research aim was to develop a new prognostic model as a combination of at least two separate variables to predict patient outcome. We focussed on the reporting and use of methods used to develop prognostic indices and risk groups from the models and measures used to determine how well the model predicted prognosis. We have set our findings in the context of the methodological literature that has studied the impact of using different methods of model predictions.

Development of good prognostic models needs researchers to provide reliable information for patient treatment decisions, including measures of the reliability and generalizability of this information.

\section{Methods}

Details of the literature search, inclusion criteria and methods in data extraction are reported in the companion paper (Mallett et al [7]). To identify articles, published subsequent to the original articles on model development, that might include external validations of the 47 prognostic models, we completed a citation search on each of the 47 original articles (30 December 2009). We used the Web of Science ${ }^{\varpi}$ citation search (citation databases: Science Citation Index expanded, Social Sciences Citation Index, Arts \& Humanities Citation Index and Conference Proceedings Citation Index Science 1990 onwards) through the ISI Web of Knowledge $^{\text {SM }}$ (Thomson Reuters 2009). Titles and abstracts for the cited references were screened and where appropriate full articles (SM).

\section{Validity assessment and data extraction}

Topics covered included: number of patients and events, source of patients, endpoints for analysis, methods and reporting of multivariate analysis, numerical and graphical presentation of model, creation of prognostic index and risk groups, model discrimination and calibration, methods of validation and usability of reported model. In a companion paper (Mallett et al [7]) we report the assessment of methods and reporting, including study design, sample size, number of patients and events, outcome definition, number and coding of variables in model, methods of selection of variables.
Twenty items were extracted by duplicate data extraction by two of three reviewers (SM, SD, RW) with reference to a third reader where necessary. One reviewer (SM) assessed all articles and all items. For eight items examination of disagreements led to refinement of data items and re-assessment by a single reviewer (SM) due to study resource and timeline limitations. If more than one model was presented in the article, the first reported in the title, abstract or text was selected.

\section{Results}

We assessed 47 articles in which prognostic models of cancer were developed for methods and reporting of the prognostic model performance [8-54]. A detailed description of the characteristics of these studies is reported in an accompanying paper (Mallett et al [7]).

Across 20 data extraction items relating to reporting of model performance measures, there was agreement in $76 \%$ of the items between readers. Over half of the differences were caused by ambiguities in the articles, the definition of the data item or where the disagreement required reference to a third reader to resolve. Examples of items frequently referred to a third reader included which methods used to create risk groups should be classified as data driven; and how much information from the final model was used to derive the prognostic index.

\section{Reporting of model}

Cox models were used in 94\% (44) of studies (Table 1) of which three articles included an additional modelling method (two on recursive partitioning analysis, one on artificial neural networks) $[10,36,48]$. Of the three articles where a Cox model was not used, a Weibull model

\section{Table 1 Numerical and graphical presentation of model} ( $n=47)$

\begin{tabular}{lc}
\hline & $\begin{array}{c}\%(\mathbf{n}) \\
\text { articles }\end{array}$ \\
\hline $\begin{array}{l}\text { Statistical model used } \\
\text { Cox only }\end{array}$ & $88(41)$ \\
$\quad$ Cox plus other (two RPA, one ANN) & $6(3)$ \\
$\quad$ Other (one Weibull, one RPA, one unclear) & $6(3)$ \\
Assumption of proportional hazards tested & $21(10)$ \\
\hline Final prognostic model reported* & $96(45)$ \\
Regression coefficient reported** & $72(34)$ \\
\hline Reproducibility of model development assessedt† & $11(5)$ \\
$\quad$ Model with same variables, not same coefficients & $9(4)$ \\
$\quad$ Model generating both new variables and & $4(2)$
\end{tabular}

† In three articles assumption of proportional hazards was not applicable as models used were RPA (recursive partitioning analysis) and ANN (artificial neural network).

* Two articles did not report the final model

** Not applicable in two articles using RPA or ANN model

t† One article used both methods to examine model reproducibility. 
was used in one article [39] and recursive partitioning analysis in another [25], and in a third article Cox modelling was rejected, but the method used was not reported [12]. The assumption of proportional hazards was reported as tested in 10 of the Cox models $[8,12,21,22,29,33,35,40,45,49]$.

The final model used to develop the prognostic index, score or to make prognostic statements was reported in 96\% (45) of the articles (Table 1). The model coefficients (hazard ratio or log hazard ratio) were reported in $72 \%(34)$ of the articles. In two articles numerous models were presented but not the model used to develop the prognostic index $[50,52]$.

\section{Reproducibility of model development}

Evaluation of model development methods in terms of both variable selection and coefficient estimates often reveals very different models can be selected based on bootstrap resampling of the patient dataset $[55,56]$. Where intermediate steps are used in model development, such as testing interaction terms or collapsing categories of variables, it might not be practicable to validate all model building steps fully [57].

In five articles the reproducibility of model development was examined (Table 1), in two articles researchers reselected the variables in the model $[18,33]$, and in four articles the coefficient values were refitted $[33,38,39,45]$. Four of these articles also included validation of the final model in addition to evaluation of model reproducibility $[18,33,39,45]$.

\section{Development of prognostic index}

Where a prognostic model is based on a large sample size and relevant variables are included in the final model, reasonable estimates of the coefficient values for each variable are likely. The prognostic index is developed as a sum of the variables from the model, weighted by their coefficient values (log hazard ratio values). If the model was developed from a small sample, coefficient values in the model are likely to be unreliable, partly due to idiosyncrasies in data that the model is developed from rather than generalizable patterns [58]. Validation of prognostic models, either internally (using the same data) or externally (using different data), is essential to understand the reliability of both the choice of variables and the values of coefficients for each variable.

The development of a prognostic index was reported in $81 \%$ (38) of the articles (Table 2). Of the nine studies where a prognostic index was not developed, four studies included risk groups $[19,25,36,48]$ and in five studies a model was developed but neither prognostic index nor risk groups were developed from the model $[10,21,22,42,54]$.
Table 2 Prognostic index, risk groups and model fitting

\begin{tabular}{lc}
\hline & $\%(\mathbf{n})$ articles \\
\hline Prognostic index (PI) developed & $81(38)$ \\
Components of final model used to create PI & \\
Same variables and coefficients & $34(13 / 38)$ \\
Same variables but not same coefficients & $21(8 / 38)$ \\
Neither same variables nor coefficients & $29(11 / 38)$ \\
Method unclear & $16(6 / 38)$ \\
\hline Risk groups are created from prognostic model & $76(36)$ \\
Method used to create risk groups & \\
Data driven & $28(10 / 36)$ \\
Equal size groups created & $14(5 / 36)$ \\
Other non data driven method & $11(4 / 36)$ \\
Method unclear & $8(3 / 36)$ \\
Method not reported & $39(14 / 36)$ \\
Number of risk groups created & $11(4 / 36)$ \\
Two risk groups & $39(14 / 36)$ \\
Three risk groups & $31(11 / 36)$ \\
Four risk groups & $11(4 / 36)$ \\
Five or more groups & $8(3 / 36)$ \\
Several different risk groupings used &
\end{tabular}

In the 38 articles where a prognostic index was developed, the final model was not reported in two articles $[50,52]$. In nine articles the coefficients of the final model were not reported $[13,18,20,29,32,39,44,50,52]$.

Appropriate methods for construction of a prognostic index from the final model were used in $34 \%$ (13 of 38) of articles [8,14-16,23,27,33,35,38,40,43,47,51], where the prognostic index was developed as the sum of the variables from the model, weighted by their coefficient values (log hazard ratio) (Table 2). In six articles the methods used to develop the prognostic index from the final model were not reported or were unclear $[17,24,26,32,39,44]$.

In $21 \%$ ( 8 of 38 ) of the articles, the variables from the final model were used to develop the prognostic index but not the coefficient values $[9,12,20,28,34,44,46,49]$, although in five of these articles authors stated their intention to use the coefficient weightings from the final model. In these eight articles that used the same variables as the final model, the following differences to the appropriate modelling methods were reported: counting factors, where equal weighting is applied to each variable was used in four articles [12,28,44,46]; a different weighting of a single variable from the weighting in the final model was assigned in one article [34]; coefficients from the univariable analysis instead of from the multivariable final model were used in one article [20]; a negative sign was missing from the coefficient in the prognostic index in one article [49]; score weightings that did not correspond to the order of the coefficients from the final model were assigned in one article [9]. 
In 11 articles researchers used neither the same variables nor coefficients as reported in the final model, for development of the prognostic index. In these articles researchers reported using the following differences to the appropriate methods: in two articles a previously published prognostic index was modified by addition of a new variable and weightings assigned to factors were derived from two different models [37,52]; between one and three variables were added into the prognostic index that were not included in the final model in five articles [11,30,45,52,53]; non-significant variables were present in the final model, but were not included in the prognostic index in three articles [17,24,41]; researchers described 'adjusting for 10 non significant variables' without including these variables in the final model in one article [13]; a significant variable was dropped from the final model from the prognostic index without explanation in one article [31]; in two articles researchers changed how variables are coded between the final model and prognostic index without apparently re-running the model to get new coefficients [13,31]; in four articles researchers derived the final model by counting variables, effectively assigning equal weighting to all factors regardless of coefficients in the model $[11,13,17,30]$. In four studies researchers used two of these methods together $[17,30,31,52]$, and in one study three of these methods were used [13].

In $95 \%$ (36 of 38) of the studies developing a prognostic index, authors reported the number of variables used, corresponding to a median of four variables (IQR 3 to 5 , range 2 to 9 ).

\section{Development of risk groups}

There is no consensus on how to create risk groups, or how many risk groups to use [59]. Risk groups can be created directly from the model or by grouping prognostic index scores into risk groups. Even where there is fair consensus on which patients would be classified as having high risk or low risk, often for clinical purposes physicians are most interested in reclassification of patients at intermediate risk, for whom treatment decisions are unclear [60]. A disadvantage of classifying risk into only two groups as opposed to three or more risk groups, is that readers of the model are unable to see how risk changes across risk groups or to estimate risks for alternative risk groups from those chosen by the original modellers.

In the absence of an a priori clinical consensus on cutpoints for prognostic risk groups, then the currently preferred method is to use a non data driven method to assign risk groupings. These methods include splitting the population into equal size groups such as thirds or quarters. This is an equally arbitrary approach but more efficient in terms of sample size than splitting the prognostic index into equal intervals, which may result in a very small number of patients in extreme risk groups.

Data driven approaches are likely to considerably overestimate model performance and are not advised. Two data driven approaches are frequently used. The minimal $P$-value approach leads to bias as it uses multiple testing to find an optimal cut point in terms of study results for a given data set $[61,62]$. The post hoc alteration of risk group cutpoints based on study results, such as a combination of risk groups similar on Kaplan Meier plots, can lead to bias as hazard coefficients are not invariant across different cutpoints of an outcome variable [63]. Similarities can be seen in post hoc alterations to the cutpoint of a diagnostic test, and how this can bias diagnostic accuracy results [64].

Risk groups were developed from the prognostic model or prognostic index in $76 \%$ (36) of studies (Table 2). In nine studies researchers used non data driven methods to develop risk groups; five used equal sized groups $[9,26,31,33,38]$; two used cutpoints from previous publications [39,52]; one used arbitrary percentiles without justification [49]; and one used categories of prognostic index [44]. In 10 studies risk groups were created using data driven methods that are likely to overestimate the separation of prognostic groups when the model is validated on external datasets, in nine by combining prognostic index scores or recursive partitioning model termini with similar risk $[15,17,23,25,27,30,35,36,48]$, in one by using a minimal $P$-value approach [47]. The methods used to develop risk groups were not reported or are unclear in 17 studies.

\section{Discrimination and calibration}

The discrimination of a prognostic model indicates how well the model separates patients who experience an event of interest from those who do not $[65,66]$. Discrimination can be presented graphically by a Kaplan Meier (KM) plot of survival for patients in different risk groups.

Several measures of discrimination have been developed including the $\mathrm{R}$ squared [3], D statistic [67], c-index [4], SEP and PSEP [68,69], K [70], NRI [6], IDI [6] and decision curve analysis [71]. Some of these tests and measures can only be applied to comparisons between categorical groups such as risk groups (for example, log rank, NRI) whereas others can be applied to continuous measures such as prognostic indices (ISI, c-index, D). Some of the methods used to assess discrimination and calibration of a logistic regression model cannot be applied to Cox models and vice versa [72].

The log rank test, although easy to implement alongside a KM graph, does not give an estimate of the magnitude of the separation of the risk groups but is used to test for a difference in survival between risk groups. 
The use of $P$-values should be avoided as $P$-values are not useful measures of how well a model separates patients with and without events [69].

The discrimination ability of a prognostic model can be presented for the data used to develop the model (Table 3) although these measures are more important in understanding the performance of models in internal and external validation (Table 4).

Table 3 summarises the presentation of discrimination for the original dataset used to develop the model in our sample of articles. Ninety-four percent (34 of 36) of studies that developed risk groups for a prognostic index presented differences in survival between risk groups using Kaplan Meier plots. The log rank test was reported in 17 studies. The percentage survival probability at a fixed time in the different risk groups was reported in 22 studies. In nine studies a measure of discrimination was reported, in seven studies the c-index was used $[14,15,33,34,46,47,49]$ and in two studies other discrimination measures were presented [38,39] (Table 3).

Model calibration describes how well the estimates of survival from the model correspond to the survival from the observed data [66,73] and can be described as a measure of the extent of bias in a model [74]. Calibration in Cox models can be presented at a specific time point, as a plot of observed proportions of events against predicted probabilities in a new dataset often based on $10^{\text {ths }}$ of risk groups [75]. In logistic regression models the Hosmer-Lemeshow test can be used, but this as a single test does not give information on how individual risk groups (for example, each $10^{\text {th }}$ of risk group) is calibrated and it has limited statistical power to assess poor calibration and is over sensitive with very large samples. We accepted model calibration on the model development dataset as presented if the percentage survival in risk groups at a fixed time point was shown for both the model predictions and the observed data.

Researchers in only one study presented calibration of the model on the model development data, at a fixed time point, as a comparison of model predictions of percentage survival in risk groups with actual survival percentages [34]. It is unclear how censored data are treated in the actual survival prediction data.

Table 3 Model performance on data used to develop model and usability* $(n=42)$

\begin{tabular}{|c|c|c|}
\hline & $\begin{array}{l}\text { Articles with risk groups } \\
\qquad(\mathrm{n}=36)\end{array}$ & $\begin{array}{l}\text { Articles with PI but no risk groups } \\
\qquad\left(\mathrm{n}=6^{* *}\right)\end{array}$ \\
\hline \multicolumn{3}{|l|}{ Presentation of discrimination of model predictionst } \\
\hline KM for risk groups & 34 & NA \\
\hline Nomogram & 2 & 4 \\
\hline Other graphical & 2 & 2 \\
\hline$\%$ survival probability at fixed timet† & 22 & 0 \\
\hline Index of discrimination (see below) & 9 & 2 \\
\hline Log rank & 17 & NA \\
\hline Unspecified $P$-value & 6 & 0 \\
\hline No presentation & 0 & 0 \\
\hline \multicolumn{3}{|l|}{ Index of discrimination\$ } \\
\hline c-index & 7 & 1 \\
\hline R squared or goodness of fit or Brier score & 1 & 1 \\
\hline $\mathrm{D}$ & 0 & 0 \\
\hline Other - K (Begg), sensitivity and specificity & 2 & 0 \\
\hline Reclassification of patient risk & 0 & 0 \\
\hline \multicolumn{3}{|l|}{ Calibration } \\
\hline Yes & 1 & 1 \\
\hline No & 35 & 5 \\
\hline \multicolumn{3}{|l|}{ Model usability from article\$\$ } \\
\hline Prognostic score or risk group can be assigned & 33 & 6 \\
\hline Survival presented for risk group and/or prognostic score & 36 & 5 \\
\hline Instructions for use suitable for physicians included & 3 & 3 \\
\hline \multicolumn{3}{|c|}{ * Five articles did not develop PI or use risk groups. } \\
\hline \multicolumn{3}{|c|}{$\begin{array}{l}\text { **Four of six articles had some commonality: three articles included the same author, one the same department. } \\
\text { †More than one option possible. } \\
\text { †† All articles have either KM or \% survival by risk group. }\end{array}$} \\
\hline$\$ \$$ Four articles are unusable, lacking one or other criteria. & \multicolumn{2}{|c|}{$\begin{array}{l}\text { \$ Two articles with risk groups report two indices of discrimination. } \\
\text { \$ Four articles are unusable, lacking one or other criteria. }\end{array}$} \\
\hline
\end{tabular}


Table 4 Model performance on validation data

\begin{tabular}{lc}
\hline & $\begin{array}{c}\text { Articles with risk } \\
\text { groups } \\
\mathbf{( n = 1 6 )}\end{array}$ \\
\hline Presentation of discrimination of model \\
predictions \\
KM for risk groups \\
Other graphical & 1 \\
\% survival probability at fixed time & 0 \\
Index of discrimination (see below) & 2 \\
Log rank & 11 \\
Unspecified P-value & 1 \\
No presentation of discrimination & 0 \\
\hline Index of discrimination\$ & 4 \\
C-index & 10 \\
R squared or goodness of fit & 4 \\
D & 0 \\
Other - $k$ (Begg), SEP (Graf) & 2 \\
Reclassification of patient risk & 0 \\
\hline Calibration & \\
Yes & 2 \\
No & 14 \\
\hline
\end{tabular}

† More than one option possible

\$ Two studies reported two indices of discrimination, one study three indices

\section{Usability of model}

We also assessed how explicit and usable the model was for those wanting to apply the model. For a model to be usable by others, we required sufficient reporting to enable a reader to compute a score or risk group, and in addition information to link this to survival probability. Ninety percent (38 of 42) of the studies fulfilled both of these requirements for a usable model (Table 3). In this assessment, the predicted survival lines in nomograms were included as providing information from the model on survival according to the prognostic score. However, instructions likely to be suitable for physicians on how to use the prognostic model, either as specific instructions or as a worked example, were included in only six articles $[8,9,18,32,39,45]$. In two articles $[18,32]$ example text for the physicians to explain to patients the interpretation of their scores was also included.

\section{Model validation}

Evaluation or validation of a prognostic model is a process of establishing that a model works satisfactorily for patients other than the original dataset used to develop the model [69]. Model validation uses the same model (that is, the same variables and same coefficients or, equivalently, the original prognostic index) to evaluate both discrimination and calibration of model predictions with observed patient outcome in new data [66].
Internal validation refers to evaluation in the same patient data, although sometimes the term internal validation includes evaluation in different patients from the same patient population. For internal validations on the same patients, methods such as bootstrapping or jackknife methods are used. Where internal validation uses data within the same population, methods include split sample and cross validation [76]. In split sample validation the data is split into a model development and testing dataset. Cross validation is an extension of split sampling methods, but where the sample split is repeated so all patients have served once in the model evaluation dataset. Although split sample and cross validation methods use different patient data to that used to develop the model, the new data is often closely related or a random split of the same dataset. Split sample methods and cross validation with fewer than 10 repeats, have been reported to provide an inferior validation method to bootstrapping for many reasons, including inefficient use of data leading to less stable model development, poor performance and bias [77]. The most stringent form of validation is external validation, where the generalizability or transportability of the model is evaluated in new patients in a separately collected population.

Model validation was reported in addition to model development in $34 \%$ (16) of studies [8-10,16,18,25, $32,33,39,40,45-47,49,51,54]$. In 15 studies, researchers validated using data from the same population; six used the bootstrap method $[33,39,45,46,49,51]$, five used a random split $[8-10,16,47]$, five cross validation $[10,18,25,39,40]$, two temporal split (Table 5). Just 11\% (5) of articles included external validation with data from a different population setting $[18,32,33,39,46]$.

\section{Table $\mathbf{5}$ Reproducibility and validation of models}

\begin{tabular}{lc}
\hline Topic & $\begin{array}{c}\% \text { ( } \mathbf{n}=\mathbf{4 7}) \\
\text { articles }\end{array}$ \\
\hline $\begin{array}{l}\text { Model validation included } \\
\text { Validation dataset* }\end{array}$ & $34(16)$ \\
$\quad \begin{array}{l}\text { Same data (bootstrap) } \\
\text { Same population, new data** }\end{array}$ & $13(6)$ \\
$\quad$ External (that is, new population setting) & $23(11)$ \\
$\quad$ Larger series including original sample & $11(5)$ \\
\hline $\begin{array}{l}\text { Validation of models } \\
\text { Final model with same coefficients and }\end{array}$ & $0(0)$ \\
$\quad$ variables & $26(12)$ \\
Unclear reporting & $9(4)$ \\
\hline $\begin{array}{l}\text { Modifications suggested to model in light of } \\
\text { validation? }\end{array}$ & $0(0)$ \\
\hline * Five studies included validation with more than one dataset. \\
** Methods used by studies were as follows: five studies used a random split, \\
two used temporal split, five used cross validation, one used the jacknife \\
method. Two studies used two and three methods respectively.
\end{tabular}


We assessed the types of dataset used in the five articles (Table 5) where external validation was reported as part of the original model development article: RCT datasets were used in two studies [33,39], a retrospective database was used in three studies $[18,32,46]$, an external validation set with some patients from an RCT and some from a consecutive patient series were used in one study [33]. In two studies researchers used external validations from the same hospital; one with RCT data [33], one with different treatments [46]. Three studies used external validation on patient data from a different hospital [18,32,39].

In 13 articles the number of patients in the validation datasets were reported (median 200, IQR 148 to 359, range 5 to 1,782). In nine articles the number of events in validation datasets were reported (median 110, IQR 65 to 149 , range 15 to 574 ) [16,18,32,33,39,45,46,49,51].

Discrimination of the model in the validation dataset was presented in $75 \%$ (12 of 16) of the articles including validation (Table 4) $[8,9,16,18,25,33,39,45-47,51]$. In 11 studies one or more indices of discrimination were reported, with the c-index reported in 10 studies and goodness of fit P-values (AIC, BIC, Cox model fit) in four studies.

In only four percent (2) of models had researchers presented any information on model calibration (Table 4) $[9,18]$. In these studies calibration plots were reported at a fixed time point for model predictions of percentage survival against actual survival percentage. None of these 16 model validations resulted in any recommendations to modify the prognostic model in the light of the validation. General rules for the need to update prognostic models before clinical application have not yet been established [73,78].

In addition to the five articles in our review that included external validations, we also searched for subsequent publications that included external validations for the 47 prognostic models, using a citation search in December 2009. For eight prognostic models [18,20,29, 34-36,46,47] subsequent articles have been published that used external patient data and reported completion of a model validation [79-92]. For three models, a model evaluation was reported in one subsequent article per model $[29,35,36]$ whereas in five models, evaluation was reported by more than one article [18,20,34,46,47]. The same authors as had developed the prognostic model had published reports of evaluation for two models $[29,36]$, whereas different authors reported evaluation for six models $[18,20,34,35,46,47]$. Overall, in the same or subsequent publications, $21 \%$ (10 of the 47 ) of models were reported as evaluated using external datasets, although the quality of evaluations was often poor and uninformative.

\section{Example of good methods and reporting}

Although the quality of the articles was generally disappointing, we particularly wish to highlight one article using good methods and good reporting [33]. This study deserves mention as researchers included: reporting of the multivariable model and its coefficients, correct use of the multivariable to develop the prognostic index, creation of risk groups using preferred methods, (for example this study used equal size groups), presentation of the model in a form usable by others, both internal and external validation of the model. Kaplan-Meier plots are reported for the validation data by risk groups and a recognised discrimination measure is reported. This same article was also the best example for our companion article on developing prognostic models (Mallett et al [7]) making it a good example for those wishing to develop prognostic models to use in combination with books and articles providing good advice on methods in prognostic modelling [3-5,69,74]

\section{Discussion}

This research has highlighted current practice in methods used to develop prognostic models for clinical predictions about the patients, and the measures of model performance reported. The quality of prognostic models depends on researchers understanding the assumptions inherent in the methods and following sound principles to ensure methods are appropriately applied [4]. Explicit reporting of methods and performance measures of models to other researchers is important to enable further model validation and transparent evaluation of clinical usefulness of models [93].

Very few articles in our study reported on how well model predictions performed, either in terms of discrimination, the ability of the model to separate patients with different outcomes, or by calibration, how accurately the model estimated the probability of outcome. Most statistical models are derived from a sequence of data driven steps leading to likely bias both in model development and the performance of a prognostic index or risk groups generated from it. Although there is no consensus on the best methods in several areas of prediction modelling, such as creation of prognostic groups, there is consensus that some methods are not advisable $[61,94]$. Unfortunately this study shows that these ill advised and biased methods are in widespread use, which will reduce the reliability of models and predictions of many prognostic models.

Though this research relates to prognostic models in cancer, problems identified in these prognostic models are not specific to cancer. Similar problems have been found in reviews of other areas of medicine [95]. This study included mostly Cox models, however the 
principles for reporting of logistic regression models are similar, even if some measures are different. Frequent use of poor methods have been reported in the development of logistic regression models [96]. A further limitation of our study was that only 47 articles were reviewed, however we judged little further value would be obtained from review of a larger number of articles.

\section{Reporting methods to develop risk groups}

There is little guidance or consensus on how to develop risk groups from a prognostic index, however using groups with equal numbers of patients or based on a justifiable clinical reason is the preferred method. Using data driven methods (based on outcomes of the data analysis itself) is not advisable although we found these methods are frequently used (in 28\% of models). Previous research has found similar inappropriate data driven methods were frequently used [59]. Preferred methods are those based on clinical consensus or arbitrary cutpoints such as quartiles of population.

In our research we found frequent use of highly biased methods to develop models and to derive prognostic indices and groups for prediction of patient risk. There are no specific guidelines on how to develop, measure performance and validate prognostic models, but there are some excellent books and articles providing advice on good and poor methodology [3-5,74].

\section{Lack of reporting of model performance}

Reporting of model performance using discrimination and calibration measures was poor (Tables 3 and 4). Only two articles reported calibration data in external validation data (Table 4).

Previous research has also found that there is poor reporting of model performance in terms of discrimination and calibration measures in logistic regression models [96-98]. In prediction models in reproductive medicine with external validation, most models reported either discrimination or calibration [95]. Discrimination is frequently reported using the c-index, equivalent to the area under the ROC curve. The c-index measures the probability that two patients, one with an event and one without, will be ranked correctly. This c-index is not related to any particular prognostic index threshold, but is integrated across all possible thresholds, whether clinically applicable or clinically absurd. The clinical applicability and meaning of the c-index has been questioned recently [6]. Model goodness of fit tests are often presented with the model development and validation, but these tests do not indicate how well a model predicts patient outcome [72]. The newer methods that describe model discrimination in terms of patient reclassification between risk groups, are starting to be used in published studies and should provide more clinically relevant information to assess model performance [99].

\section{Internal and external validation}

Validation of models is essential to establish whether a prognostic model is likely to provide useful classification of patient risk. External validation is an essential prerequisite before models are applied in clinical practice, preferably by external investigators $[66,76]$. We found $34 \%$ of articles included some validation, but external data from a new patient population was used in only $11 \%$ of studies. Reported external evaluation of eight models was found in subsequent publications. In total only $21 \%$ (10 models) were reported as externally validated in either the original articles or in the subsequent four years. Other research has found that a large range, $0 \%$ to $52 \%$, of articles where a prediction model was developed, included either internal or external validation [93,95-98].

Articles in this study did not report using multiple imputation methods to address missing prognostic variable data. Several articles confirm that only complete case data are included in model development, indicating the presence of selection bias in the model. Ongoing methodological research provides guidelines on the use of multiple imputation for missing data [100], development and validation of models with missing data [101] and how to apply models when missing data are present [102].

\section{The implications for clinical medicine}

Prognostic models are developed to provide objective probability estimates to complement clinical intuition of the physician and guidelines [73]. Many published prognostic models have been developed using poor methodological choices that may adversely affect model performance. This may help to explain why so few models are used in clinical practice. Appropriate choice and use of prognostic models in clinical practice requires model validation and reporting appropriate measures of model performance in order to assess reliability and generalizability of models.

\section{Conclusions}

Development, validation and assessment of the performance of prognostic models are complex, and depend on researchers understanding statistical methods and how to apply them appropriately. We found poor reporting of the methods used to develop models and details of the models. Questionable methods are widely used to develop prognostic indices and few models are validated, even using internal validation methods that do not require additional datasets. 


\section{Abbreviations}

AIC: Akaike information criterion; ANN: artificial neural network; BIC: Bayesian information criterion; DFS: disease free survival; EPV: events per variable; IQR: interquartile range; KM: Kaplan Meier plot; MeSH: Medical subject heading from U.S. National Library of Medicine's controlled vocabulary; NLM: National Library of Medicine; PI: prognostic index; RCT: randomised controlled trial; RPA: recursive partitioning analysis.

\section{Acknowledgements}

We thank Gary Collins for helpful comments on the manuscript. SM, DGA RW and SD are supported by Cancer Research UK. PR is supported by the UK Medical Research Council (U.1228.06.001.00002.01).

\section{Author details}

${ }^{1}$ Centre for Statistics in Medicine, Wolfson College Annexe, University of Oxford, Linton Road, Oxford, OX2 6UD, UK. ${ }^{2}$ MRC Clinical Trials Unit, 222 Euston Road, London NW1 2DA, UK.

\section{Authors' contributions}

SM contributed to design, carried out data extraction on all articles and items, compiled results and drafted the manuscript. PR and DGA contributed to the design and drafting of the article. RW and SD carried out duplicate data extraction for some data items and commented on the manuscript.

\section{Authors' informations}

All authors are medical statisticians.

\section{Competing interests}

The authors declare that they have no competing interests.

Received: 19 February 2010 Accepted: 30 March 2010

Published: 30 March 2010

\section{References}

1. Hemingway $\mathrm{H}$ : Prognosis research: why is Dr. Lydgate still waiting? J Clin Epidemiol 2006, 59:1229-1238

2. Moons KG, Royston P, Vergouwe $Y$, Grobbee DE, Altman DG: Prognosis and prognostic research: what, why, and how? BMJ 2009, 338:b375.

3. Steyerberg EW: Clinical prediction models New York: Springer 2008.

4. Harrell FE Jr: Regression Modeling Strategies:with applications to linear models, logistic regression and survival analysis New York: Springer-Verlag 2001.

5. Royston P, Sauerbrei W: Multivariable model-building: A pragmatic approach to regression analysis based on fractional polynomials for modelling continuous variables John Wiley \& Sons Ltd; Chichester UK, 12008.

6. Pencina MJ, D'Agostino RB Sr, D'Agostino RB Jr, Vasan RS: Evaluating the added predictive ability of a new marker: from area under the ROC curve to reclassification and beyond. Stat Med 2008, 27:157-172.

7. Mallett S, Royston P, Dutton S, Waters R, Altman D: Reporting methods in studies developing prognostic models in cancer: a review. BMC Medicine 2010, 8:20.

8. Kim HL, Seligson D, Liu X, Janzen N, Bui MH, Yu H, Shi T, Belldegrun AS, Horvath S, Figlin RA: Using tumor markers to predict the survival of patients with metastatic renal cell carcinoma. J Urol 2005, 173:1496-1501.

9. Hoang $T, X u R$, Schiller $J H$, Bonomi $P$, Johnson DH: Clinical model to predict survival in chemonaive patients with advanced non-small-cell lung cancer treated with third-generation chemotherapy regimens based on eastern cooperative oncology group data. J Clin Oncol 2005, 23:175-183.

10. Jerez JM, Franco L, Alba E, Llombart-Cussac A, Lluch A, Ribelles N, Munarriz B, Martin M: Improvement of breast cancer relapse prediction in high risk intervals using artificial neural networks. Breast Cancer Res Treat 2005, 94:265-272.

11. Mekhail TM, Abou-Jawde RM, Boumerhi G, Malhi S, Wood L, Elson P, Bukowski R: Validation and extension of the Memorial Sloan-Kettering prognostic factors model for survival in patients with previously untreated metastatic renal cell carcinoma. J Clin Oncol 2005, 23:832-841.

12. North RB, LaRocca VR, Schwartz J, North CA, Zahurak M, Davis RF McAfee PC: Surgical management of spinal metastases: analysis of prognostic factors during a 10-year experience. J Neurosurg Spine 2005, 2:564-573
13. Smith BD, Smith GL, Cooper DL, Wilson LD: The cutaneous B-cell lymphoma prognostic index: a novel prognostic index derived from a population-based registry. J Clin Oncol 2005, 23:3390-3395.

14. Solsona E, Iborra I, Dumont R, Rubio J, Casanova JL, Almenar S: Risk groups in patients with bladder cancer treated with radical cystectomy: statistical and clinical model improving homogeneity. J Urol 2005 174:1226-1230

15. Leibovich BC, Cheville JC, Lohse CM, Zincke H, Frank I, Kwon ED, Merchan JR, Blute ML: A scoring algorithm to predict survival for patients with metastatic clear cell renal cell carcinoma: a stratification tool for prospective clinical trials. J Urol 2005, 174:1759-1763.

16. Liao CS, Yang KC, Yen MF, Hsiu-Hsi CT: Time-varying predictors for clinical surveillance of small hepatocellular carcinoma. Cancer 2005, 11:226-233.

17. Khaled H, El Hattab O, Moneim DA, Kassem HA, Morsi A, Sherif G, Darwish T, Gaafar R: A prognostic index (bladder prognostic index) for bilharzial-related invasive bladder cancer. Urol Oncol 2005, 23:254-260.

18. Stephenson AJ, Scardino PT, Eastham JA, Bianco FJ Jr, Dotan ZA, DiBlasio CJ, Reuther A, Klein EA, Kattan MW: Postoperative nomogram predicting the 10-year probability of prostate cancer recurrence after radical prostatectomy. J Clin Oncol 2005, 23:7005-7012.

19. Lin YC, Chen SC, Chang HK, Hsueh S, Tsai CS, Lo YF, Hwang TL, Chen MF: Identifying good prognosis group of breast cancer patients with 1-3 positive axillary nodes for adjuvant cyclophosphamide, methotrexate and 5-fluorouracil (CMF) chemotherapy. Jpn J Clin Oncol 2005, 35:514-519.

20. Linden van der YM, Dijkstra SP, Vonk EJ, Marijnen CA, Leer JW: Prediction of survival in patients with metastases in the spinal column: results based on a randomized trial of radiotherapy. Cancer 2005, 103:320-328.

21. Hennessy BT, Hortobagyi GN, Rouzier R, Kuerer H, Sneige N, Buzdar AU, Kau SW, Fornage B, Sahin A, Broglio K, Singletary SE, Valero V: Outcome after pathologic complete eradication of cytologically proven breast cancer axillary node metastases following primary chemotherapy. J Clin Oncol 2005, 23:9304-9311.

22. Stracci F, La Rosa F, Falsettini E, Ricci E, Aristei C, Bellezza G, Bolis GB, Fenocchio D, Gori S, Rulli A, Mastrandrea V: A population survival model for breast cancer. Breast 2005, 14:94-102.

23. Kikuchi E, Horiguchi Y, Nakashima J, Hatakeyama N, Matsumoto M, Nishiyama T, Murai M: Lymphovascular invasion independently predicts increased disease specific survival in patients with transitional cell carcinoma of the upper urinary tract. J Urol 2005, 174:2120-2123.

24. Kato H, Yoshimatsu K, Ishibashi K, Watanabe K, Shiozawa S, Tsuchiya A, Yamada R, Sakamoto T, Haga S: A new staging system for colorectal carcinoma with liver metastasis. Anticancer Res 2005, 25:1251-1255.

25. Truong PT, Lesperance M, Culhaci A, Kader HA, Speers $C H$, Olivotto IA: Patient subsets with T1-T2, node-negative breast cancer at high locoregional recurrence risk after mastectomy. Int J Radiat Oncol Biol Phys 2005, 62:175-182.

26. Peccatori J, Barkholt $L$, Demirer $T$, Sormani MP, Bruzzi $P$, Ciceri $F$, Zambelli $A$ Da Prada GA, Pedrazzoli P, Siena S, Massenkeil G, Martino R, Lenhoff S, Corradini P, Rosti G, Ringden O, Bregni M, Niederwieser D: Prognostic factors for survival in patients with advanced renal cell carcinoma undergoing nonmyeloablative allogeneic stem cell transplantation. Cancer 2005, 104:2099-2103.

27. Hahn T, Benekli M, Wong C, Moysich KB, Hyland A, Michalek AM, Alam A, Baer MR, Bambach B, Czuczman MS, Wetzler M, Becker JL, McCarthy PL: A prognostic model for prolonged event-free survival after autologous or allogeneic blood or marrow transplantation for relapsed and refractory Hodgkin's disease. Bone Marrow Transplant 2005, 35:557-566.

28. Claude L, Perol D, Ray-Coquard I, Petit T, Blay JY, Carrie C, Bachelot T: Lymphopenia: a new independent prognostic factor for survival in patients treated with whole brain radiotherapy for brain metastases from breast carcinoma. Radiother Oncol 2005, 76:334-339.

29. Colinet B, Jacot W, Bertrand D, Lacombe S, Bozonnat MC, Daures JP, Pujol JL: A new simplified comorbidity score as a prognostic factor in non-small-cell lung cancer patients: description and comparison with the Charlson's index. Br J Cancer 2005, 93:1098-1105.

30. Molica S, Mauro FR, Callea V, Gentile M, Giannarelli D, Lopez M, Lauria F, Rotoli B, Montanaro M, Cortelezzi A, Liso V, Mandelli F, Foa R: A genderbased score system predicts the clinical outcome of patients with early B-cell chronic lymphocytic leukemia. Leuk Lymphoma 2005, 46:553-560. 
31. Matsui Y, Utsunomiya N, Ichioka K, Ueda N, Yoshimura K, Terai A, Arai Y: Risk factors for subsequent development of bladder cancer after primary transitional cell carcinoma of the upper urinary tract. Urology 2005, 65:279-283.

32. Sorbellini M, Kattan MW, Snyder ME, Reuter V, Motzer R, Goetzl M, McKiernan J, Russo P: A postoperative prognostic nomogram predicting recurrence for patients with conventional clear cell renal cell carcinoma. J Urol 2005, 173:48-51.

33. Steyerberg EW, Homs MY, Stokvis A, Essink-Bot ML, Siersema PD: Stent placement or brachytherapy for palliation of dysphagia from esophageal cancer: a prognostic model to guide treatment selection. Gastrointest Endosc 2005, 62:333-340.

34. Cooperberg MR, Pasta DJ, Elkin EP, Litwin MS, Latini DM, Du Chane J, Carroll PR: The University of California, San Francisco Cancer of the Prostate Risk Assessment score: a straightforward and reliable preoperative predictor of disease recurrence after radical prostatectomy. J Urol 2005, 173:1938-1942.

35. Breems DA, Van Putten WL, Huijgens PC, Ossenkoppele GJ, Verhoef GE, Verdonck LF, Vellenga E, De Greef GE, Jacky E, Lelie Van der J, Boogaerts MA, Lowenberg B: Prognostic index for adult patients with acute myeloid leukemia in first relapse. J Clin Oncol 2005, 23:1969-1978.

36. Langendijk JA, Slotman BJ, Waal van der I, Doornaert P, Berkof J, Leemans CR: Risk-group definition by recursive partitioning analysis of patients with squamous cell head and neck carcinoma treated with surgery and postoperative radiotherapy. Cancer 2005, 104:1408-1417.

37. Klemke CD, Mansmann U, Poenitz N, Dippel E, Goerdt S: Prognostic factors and prediction of prognosis by the CTCL Severity Index in mycosis fungoides and Sezary syndrome. Br J Dermatol 2005, 153:118-124.

38. Bower M, Gazzard B, Mandalia S, Newsom-Davis T, Thirlwell C, Dhillon T, Young AM, Powles T, Gaya A, Nelson M, Stebbing J: A prognostic index for systemic AIDS-related non-Hodgkin lymphoma treated in the era of highly active antiretroviral therapy. Ann Intern Med 2005, 143:265-273.

39. Mariani L, Miceli R, Lusa L, Di Bartolomeo M, Bozzetti F: A modified prognostic score for patients with curatively resected gastric cancer. Tumori 2005, 91:221-226.

40. Schmidt H, Bastholt L, Geertsen P, Christensen IJ, Larsen S, Gehl J, Maase von der $\mathrm{H}$ : Elevated neutrophil and monocyte counts in peripheral blood are associated with poor survival in patients with metastatic melanoma: a prognostic model. Br J Cancer 2005, 93:273-278.

41. Katagiri H, Takahashi M, Wakai K, Sugiura H, Kataoka T, Nakanishi K: Prognostic factors and a scoring system for patients with skeletal metastasis. J Bone Joint Surg Br 2005, 87:698-703.

42. Aa van der MN, van Leenders GJ, Steyerberg EW, van Rhijn BW, Jobsis AC, Zwarthoff EC, Kwast van der TH: A new system for substaging pT1 papillary bladder cancer: a prognostic evaluation. Hum Pathol 2005, 36:981-986.

43. Saisho T, Okusaka T, Ueno H, Morizane C, Okada S: Prognostic factors in patients with advanced biliary tract cancer receiving chemotherapy. Hepatogastroenterology 2005, 52:1654-1658.

44. Rubio L, Vera-Sempere FJ, Lopez-Guerrero JA, Padilla J, Moreno-Baylach MJ: A risk model for non-small cell lung cancer using clinicopathological variables, angiogenesis and oncoprotein expression. Anticancer Res 2005, 25:497-504.

45. Mariani L, Miceli R, Kattan MW, Brennan MF, Colecchia M, Fiore M Casali PG, Gronchi A: Validation and adaptation of a nomogram for predicting the survival of patients with extremity soft tissue sarcoma using a three-grade system. Cancer 2005, 103:402-408.

46. Tateishi R, Yoshida H, Shiina S, Imamura H, Hasegawa K, Teratani T, Obi S, Sato S, Koike Y, Fujishima T, Makuuchi M, Omata M: Proposal of a new prognostic model for hepatocellular carcinoma: an analysis of 403 patients. Gut 2005, 54:419-425.

47. Yildirim E: A model for predicting outcomes in patients with differentiated thyroid cancer and model performance in comparison with other classification systems. J Am Coll Surg 2005, 200:378-392.

48. Shulman MJ, Benaim EA: Prognostic model of event-free survival for patients with androgen-independent prostate carcinoma. Cancer 2005, 103:2280-2286

49. Gronlund B, Christensen IJ, Bulow-Lehnsby AL, Engelholm SA, Hansen HH, Hogdall C: Recurrent epithelial ovarian cancer: validation and improvement of an established prognostic index. Eur J Obstet Gynecol Reprod Biol 2005, 123:98-106.
50. Hasebe T, Sasaki S, Imoto S, Wada N, Ishii G, Ochiai A: Primary tumourvessel tumour-nodal tumour classification for patients with invasive ductal carcinoma of the breast. Br J Cancer 2005, 92:847-856.

51. Slovin SF, Wilton AS, Heller G, Scher HI: Time to detectable metastatic disease in patients with rising prostate-specific antigen values following surgery or radiation therapy. Clin Cancer Res 2005, 11:8669-8673.

52. Meyer JS, Alvarez C, Milikowski C, Olson N, Russo I, Russo J, Glass A, Zehnbauer BA, Lister K, Parwaresch R: Breast carcinoma malignancy grading by Bloom-Richardson system vs proliferation index: reproducibility of grade and advantages of proliferation index. Mod Pathol 2005, 18:1067-1078.

53. Froehner M, Koch R, Litz RJ, Haase M, Klenk U, Oehlschlaeger S, Baretton GB, Wirth MP: Comparison of tumor- and comorbidity-related predictors of mortality after radical prostatectomy. Scand J Urol Nephrol 2005, 39:449-454.

54. Nathan SS, Healey JH, Mellano D, Hoang B, Lewis I, Morris CD, Athanasian EA, Boland PJ: Survival in patients operated on for pathologic fracture: implications for end-of-life orthopedic care. J Clin Oncol 2005, 23:6072-6082.

55. Altman DG, Andersen PK: Bootstrap investigation of the stability of a Cox regression model. Stat Med 1989, 8:771-783.

56. Sauerbrei W, Royston P: Modelling to extract more information from clinical trials data: On some roles for the bootstrap. Stat Med 2007, 26:4989-5001.

57. Steyerberg EW, Bleeker SE, Moll HA, Grobbee DE, Moons KG: Internal and external validation of predictive models: a simulation study of bias and precision in small samples. J Clin Epidemiol 2003, 56:441-447.

58. Steyerberg EW: Study design for prediction models. Clinical Prediction Models New York: Springer 2008, Chapter 3.

59. Altman DG: Prognostic models: a methodological framework and review of models for breast cancer. Cancer Invest 2009, 27:235-243.

60. Cook NR: Comments on 'Evaluating the added predictive ability of a new marker: From area under the ROC curve to reclassification and beyond' by M. J. Pencina et al., Statistics in Medicine (DOI: 10.1002/ sim.2929). Stat Med 2008, 27:191-195.

61. Altman DG, Lausen B, Sauerbrei W, Schumacher M: Dangers of using "optimal" cutpoints in the evaluation of prognostic factors. J Nat/ Cancer Inst 1994, 86:829-835.

62. Royston P, Altman DG, Sauerbrei W: Dichotomizing continuous predictors in multiple regression: a bad idea. Stat Med 2006, 25:127-141.

63. Ragland DR: Is there really a conceptual difference in choosing the cutpoint for dichotomizing outcome and predictor variables? Epidemiology 1993, 4:276

64. Ewald B: Post hoc choice of cut points introduced bias to diagnostic research. J Clin Epidemiol 2006, 59:798-801.

65. McGeechan K, Macaskill P, Irwig L, Liew G, Wong TY: Assessing new biomarkers and predictive models for use in clinical practice: a clinician's guide. Arch Intern Med 2008, 168:2304-2310.

66. Altman DG, Vergouwe $Y$, Royston P, Moons KG: Prognosis and prognostic research: validating a prognostic model. BMJ 2009, 338:b605.

67. Royston P, Sauerbrei W: A new measure of prognostic separation in survival data. Stat Med 2004, 23:723-748.

68. Graf E, Schmoor C, Sauerbrei W, Schumacher M: Assessment and comparison of prognostic classification schemes for survival data. Stat Med 1999, 18:2529-2545.

69. Altman DG, Royston P: What do we mean by validating a prognostic model? Stat Med 2000, 19:453-473.

70. Begg CB, Cramer LD, Venkatraman ES, Rosai J: Comparing tumour staging and grading systems: a case study and a review of the issues, using thymoma as a model. Stat Med 2000, 19:1997-2014

71. Vickers AJ, Elkin EB: Decision curve analysis: a novel method for evaluating prediction models. Med Decis Making 2006, 26:565-574.

72. Steyerberg EW: Evaluation of performance. Clinical Prediction Models New York: Springer 2008, Chapter 15.

73. Moons KG, Altman DG, Vergouwe $Y$, Royston P: Prognosis and prognostic research: application and impact of prognostic models in clinical practice. BMJ 2009, 338:b606.

74. Harrell FE Jr, Lee KL, Mark DB: Multivariable prognostic models: issues in developing models, evaluating assumptions and adequacy, and measuring and reducing errors. Stat Med 1996, 15:361-387. 
75. van Houwelingen HC: Validation, calibration, revision and combination of prognostic survival models. Stat Med 2000, 19:3401-3415.

76. Justice AC, Covinsky KE, Berlin JA: Assessing the generalizability of prognostic information. Ann Intern Med 1999, 130:515-524

77. Steyerberg EW: Validation of prediction models. Clinical Prediction Models Chapter 17 New York: Springer 2008, Chapter 17.

78. Toll DB, Janssen K, Vergouwe Y, Moons KG: Validation, updating and impact of clinical prediction rules: a review. J Clin Epidemiol 2008, 61:1085-1094.

79. Giles F, Verstovsek S, Garcia-Manero G, Thomas D, Ravandi F, Wierda W, Ferrajoli A, Kornblau S, Jabbour E, Shan J, O'Brien S, Albitar M, Kantarjian H: Validation of the European Prognostic Index for younger adult patients with acute myeloid leukaemia in first relapse. Br J Haematol 2006, 134:58-60

80. Chow E, Harris K, Fung K: Successful validation of a survival prediction model in patients with metastases in the spinal column. Int J Radiat Oncol Biol Phys 2006, 65:1522-1527.

81. May M, Knoll N, Siegsmund M, Fahlenkamp D, Vogler H, Hoschke B, Gralla O: Validity of the CAPRA score to predict biochemical recurrencefree survival after radical prostatectomy. Results from a European multicenter survey of 1,296 patients. J Urol 2007, 178:1957-1962.

82. Jonkman A, Kaanders JH, Terhaard CH, Hoebers FJ, Ende van den PL, Wijers $O B$, Verhoef $L C$, de Jong MA, Leemans $C R$, Langendijk JA: Multicenter validation of recursive partitioning analysis classification for patients with squamous cell head and neck carcinoma treated with surgery and postoperative radiotherapy. Int I Radiat Oncol Biol Phys 2007, 68:119-125.

83. Lang BH, Lo CY, Chan WF, Lam KY, Wan KY: Staging systems for follicular thyroid carcinoma: application to 171 consecutive patients treated in a tertiary referral centre. Endocr Relat Cancer 2007, 14:29-42.

84. Jacot W, Colinet B, Bertrand D, Lacombe S, Bozonnat MC, Daures JP, Pujol JL: Quality of life and comorbidity score as prognostic determinants in non-small-cell lung cancer patients. Ann Oncol 2008, 19:1458-1464.

85. Cooperberg MR: Prostate cancer risk assessment: choosing the sharpest tool in the shed. Cancer 2008, 113:3062-3066.

86. Zhao KH, Hernandez DJ, Han M, Humphreys EB, Mangold LA, Partin AW: External validation of University of California, San Francisco, Cancer of the Prostate Risk Assessment score. Urology 2008, 72:396-400.

87. Chung H, Kudo M, Takahashi S, Hagiwara S, Sakaguchi Y, Inoue T, Minami Y, Ueshima K, Fukunaga T, Matsunaga T: Comparison of three current staging systems for hepatocellular carcinoma: Japan integrated staging score, new Barcelona Clinic Liver Cancer staging classification, and Tokyo score. J Gastroenterol Hepatol 2008, 23:445-452.

88. Leithner A, Radl R, Gruber G, Hochegger M, Leithner K, Welkerling H, Rehak $P$, Windhager R: Predictive value of seven preoperative prognostic scoring systems for spinal metastases. Eur Spine J 2008, 17:1488-1495.

89. Schroeck FR, Aronson WJ, Presti JC Jr, Terris MK, Kane CJ, Amling CL, Freedland SJ: Do nomograms predict aggressive recurrence after radical prostatectomy more accurately than biochemical recurrence alone? BJU Int 2009, 103:603-608.

90. Eggener SE, Vickers AJ, Serio AM, Donovan MJ, Khan FM, Bayer-Zubek V, Verbel D, Cordon-Cardo C, Reuter VE, Bianco FJ Jr, Scardino PT: Comparison of models to predict clinical failure after radical prostatectomy. Cancer 2009, 115:303-310

91. Chen CH, Hu FC, Huang GT, Lee PH, Tsang YM, Cheng AL, Chen DS, Wang JD, Sheu JC: Applicability of staging systems for patients with hepatocellular carcinoma is dependent on treatment method-analysis of 2010 Taiwanese patients. Eur J Cancer 2009, 45:1630-1639.

92. Huo TI, Hsia CY, Huang YH, Lin HC, Lee PC, Lui WY, Chiang JH, Chiou YY, Loong CC, Lee SD: Selecting a short-term prognostic model for hepatocellular carcinoma: comparison between the model for end-stage liver disease (MELD), MELD-sodium, and five cancer staging systems. J Clin Gastroenterol 2009, 43:773-781.

93. Bagley SC, White H, Golomb BA: Logistic regression in the medical literature: standards for use and reporting, with particular attention to one medical domain. J Clin Epidemiol 2001, 54:979-985.

94. Sun GW, Shook TL, Kay GL: Inappropriate use of bivariable analysis to screen risk factors for use in multivariable analysis. J Clin Epidemiol 1996, 49:907-916.
95. Leushuis E, Steeg van der JW, Steures P, Bossuyt PM, Eijkemans MJ, Veen van der F, Mol BW, Hompes PG: Prediction models in reproductive medicine: a critical appraisal. Hum Reprod Update 2009, 15:537-552

96. Mikolajczyk RT, Disilvestro A, Zhang J: Evaluation of logistic regression reporting in current obstetrics and gynecology literature. Obstet Gynecol 2008, 111:413-419.

97. Mushkudiani NA, Hukkelhoven CW, Hernandez AV, Murray GD, Choi SC, Maas Al, Steyerberg EW: A systematic review finds methodological improvements necessary for prognostic models in determining traumatic brain injury outcomes. J Clin Epidemiol 2008, 61:331-343.

98. Ottenbacher KJ, Ottenbacher HR, Tooth L, Ostir GV: A review of two journals found that articles using multivariable logistic regression frequently did not report commonly recommended assumptions. J Clin Epidemiol 2004, 57:1147-1152.

99. Collins GS, Altman DG: An independent external validation and evaluation of QRISK cardiovascular risk prediction: a prospective open cohort study. BMJ 2009, 339:b2584.

100. Marshall A, Altman DG, Holder RL, Royston P: Combining estimates of interest in prognostic modelling studies after multiple imputation: current practice and guidelines. BMC Med Res Methodol 2009, 9:57.

101. Vergouwe Y, Royston P, Moons KG, Altman DG: Development and validation of a prediction model with missing predictor data: a practical approach. J Clin Epidemiol 2009, 63:205-214.

102. Janssen KJ, Vergouwe Y, Donders RT, Harrell FE Jr, Chen Q, Grobbee DE, Moons KG: Dealing with missing predictor variables when applying clinical prediction models. Clinical Chemistry 2009

\section{Pre-publication history}

The pre-publication history for this paper can be accessed here: http://www. biomedcentral.com/1741-7015/8/21/prepub

doi:10.1186/1741-7015-8-21

Cite this article as: Mallett et al:: Reporting performance of prognostic models in cancer: a review. BMC Medicine 2010 8:21.

\section{Submit your next manuscript to BioMed Central and take full advantage of:}

- Convenient online submission

- Thorough peer review

- No space constraints or color figure charges

- Immediate publication on acceptance

- Inclusion in PubMed, CAS, Scopus and Google Scholar

- Research which is freely available for redistribution 